\title{
Discovery of tetraploidy in a mammal
}

\section{The red viscacha rat is unaffected by having double the usual number of chromosomes.}

olyploidy, or having more than a pair of each type of chromosome, is considered to be unlikely in mammals because it would disrupt the mechanism of dosage compensation that normally inactivates one $\mathrm{X}$ chromosome in females ${ }^{1}$. Also, any imbalance in chromosome number should affect the normal developmental processes and therefore constitute an evolutionary end, as in triploid humans ${ }^{2}$.

Nevertheless, genetic evidence indicates that the red viscacha rat, Tympanoctomys barrerae (Octodontidae) ${ }^{3}$, is tetraploid. T. barrerae, which is a highly specialized desert rodent ${ }^{4}$, has the largest chromosome complement in mammals ${ }^{5}$ with a single XY sexchromosome system (Fig. 1). Although little is known about meiotic chromosome pairing in T. barrerae, the constant diploid number found in 13 specimens examined at three localities in Argentina indicates that segregation occurs normally.

In mammals without excessive constitutive heterochromatin in their chromosomal complement, nuclear DNA content is relatively constant, ranging from 6 to 8 picograms of DNA (mean, $6.3 \mathrm{pg})^{6}$. Analysis of somatic tissues by flow cytometry indicates that $T$. barrerae has a genome of $16.8 \mathrm{pg}$, which is twice the DNA content of its closest relatives (for example, $8.2 \mathrm{pg}$ and $7.6 \mathrm{pg}$ for Octodontomys gliroides and Octomys mimax, respectively) and of most other mammals.

The huge genome of T. barrerae cannot be explained by an increased amount of heterochromatin because it is restricted to the centromere region of chromosomes. Furthermore, the diploid number in $T$. barrerae is less than that would be expected $(2 N=112)$ from a simple duplication of the karyotype seen in its closest relatives, indicating that chromosomal material has been eliminated.

The size of the sperm head in mammals depends on its DNA content, as exemplified by the abnormally large and diploid sperm of rabbits and bulls ${ }^{7}$. The enormous broad and spatulate sperm head of $T$. barrerae (Fig. 2) is $14.1( \pm 0.6)$ by $13.4( \pm 0.5)$ micrometres in size, and gametic genome estimates are consistent with somatic estimates (Octomys mimax, $4.32 \pm 0.25$ pg; Spalacopus cyanus, $3.54 \pm 0.27$ pg; T. barrerae, $9.2 \pm 0.72 \mathrm{pg}$ ).

As would be expected in a tetraploid organism, significantly larger somatic-cell diameters were recorded. A highly significant paired $t$-test $(P<0.001)$ supported the idea that there was a difference in the maximum diameter of liver cells $(N=150)$

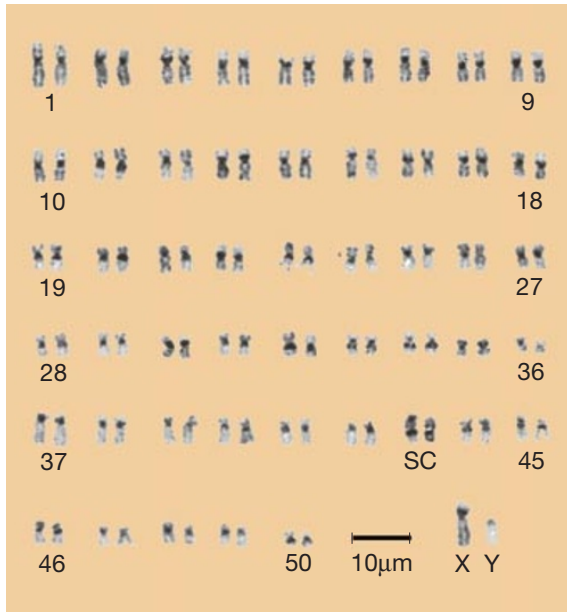

Figure $1 \mathrm{C}$-banded karyotype of a male Tympanoctomys barrerae from Mendoza, Argentina $(4 N=102$; fundamental number of autosomal arms is 200). The karyotype includes 36 pairs of metacentric to submetacentric chromosomes and 14 pairs of subtelocentric autosomes. The $X$ chromosome is the largest element, present in two copies in females. The $Y$ chromosome, which is medium-sized, is the only acrocentric element of the karyotype. Note that the marker chromosome pair of the family Octodontidae (secondary constriction, SC), which has a band of interstitial heterochromatin, is present in only two copies, not four, as would be expected following a perfect duplication.

between $T$. barrerae $(26.1 \pm 3.8 \mu \mathrm{m})$ and Abrocoma bennetti $(22.3 \pm 3.5 \mu \mathrm{m})$ or Octodon lunatus $(21.3 \pm 2.7 \mu \mathrm{m})$.

The müllerian explanation for the rarity of tetraploidy among animals with XY sexchromosome systems emphasizes inviability or sterility resulting from an altered dosagesensitive regulatory mechanism ${ }^{8}$. Sex determination in mammals depends on the testis-determining locus, but in the germ line it is affected by dosage of $\mathrm{X}$-chromosome-linked genes 9 . The fact that polyploid cells have more than one active X chromosome indicates that the signal to initiate inactivation through heterochromatization may be dependent on the critical X-toautosomal chromosome ratio.

If there is an evolutionary elimination of chromosomes, as we propose, then the X-toautosome ratio should not depend on the whole set of autosomes, but rather on some critical autosomes needed in only one copy of the gamete. Thus, the disomic condition of the X chromosome in female $T$. barrerae is either sufficient or possibly the only means by which the tetraploid can escape arrested gonadal development. This idea is supported by the inviability or infertility that affects human triploids, who do not have enough diploid cells to undergo meiosis ${ }^{10}$.

Investigation of the chromosomal architecture (by studying meiotic pairing and in

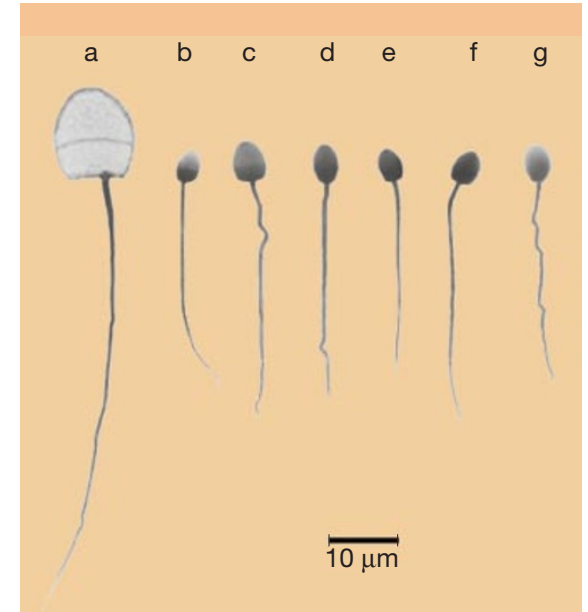

Figure 2 Bright-field photomicrograph of sperm cells from different genera in the families Octodontidae and Abrocomidae. a, Tympanoctomys barrerae; b, Aconaemys fuscus; c, Octodon degus; d, Spalacopus cyanus; e, Octomys mimax; f, Octodontomys gliroides; $\mathbf{g}$, Abrocoma bennetti.

situ hibridization) and genome organization (by looking for single-dose genes and clusters of linked duplicated genes) of $T$. barrerae should enable this tetraploidy in $T$. barrerae to be verified and will provide new insights into the mechanisms underlying dosage compensation, sex determination, regulation of gene expression and development in mammals. The role of wholegenome duplication in triggering evolutionary novelty is exemplified by this unique tetraploid mammal ${ }^{3}$.

Milton H. Gallardo*, J. W. Bickham $\dagger$,

R. L. Honeycutt $\dagger$, R. A. Ojeda $\ddagger$,

N. Köhler ${ }^{\star}$

*Instituto de Ecología y Evolución,

Universidad Austral de Chile,

Casilla 567, Valdivia, Chile

e-mail:mgallard@uach.cl

$\dagger$ Department of Wildlife and Fisheries Sciences,

Texas A\&M University, College Station,

Texas 77843, USA

$¥$ Instituto Argentino de Investigación de Zonas

Áridas, Cricyt, GIB Conicet Casilla de Correo 507, 5500 Mendoza, Argentina

1. Orr, H. A. Am. Nat. 136, 759-770 (1990).

2. Niebuhr, E. Humangenetik 21, 103-125 (1974).

3. Gallardo, M. H. in Chromosomes Today Vol 12 (eds Henríques-Gil, N., Parker, J. S \& Puertas, M. J.) 347-365 (Chapman \& Hall, London, 1997).

4. Ojeda, R. A. et al. J. Arid Environ. 41, 443-452 (1999).

5. Contreras, L. C., Torres-Mura, J. C. \& Spotorno, A. E. Experientia 46, 506-508 (1990).

6. Vinogradov, A. E. Cytometry 31, 100-109 (1998).

7. Ferrari, M. R., Spirito, S. E., Giuliano, S. M. \& Fernández, H. A. Andrologia 30, 85-89 (1998).

8. Müller, H. Am. Nat. 59, 346-353 (1925).

9. Parkhurst, S. M. \& Meneely, P. M. Science 264, 924-932 (1994).

10. Ohno, S., Kittrell, W. A., Christian, L. C., Stenius, C. \& Witts, G. A. Cytogenetics 2, 42-49 (1963). 